\title{
Galline Experimental Organism Diagnosis
}

National Cancer Institute

\section{Source}

National Cancer Institute. Galline Experimental Organism Diagnosis. NCI Thesaurus.

Code C134534.

A condition that is relevant to either disease states or models of disease in chickens. 